\title{
About THE EdTors
}

John Bell is Professor of Comparative Law and Co-Director of the Centre for European Legal Studies at the Faculty of Law, University of Cambridge. He is a Fellow of Pembroke College, Cambridge.

Claire Kilpatrick is a University Lecturer in Law and Co-Director of the Centre for European Legal Studies at the Faculty of Law, University of Cambridge. She is a Fellow of Emmanuel College, Cambridge. 
Founding EdiTors

Alan Dashwood

Angela Ward

EDITORIAL ADVISORY BOARD

Albertina Albors-Llorens

Catherine Barnard

John Bell

Alan Dashwood

Simon Deakin

David Feldman

Richard Fentiman

Angus Johnston

Claire Kilpatrick

John Spencer

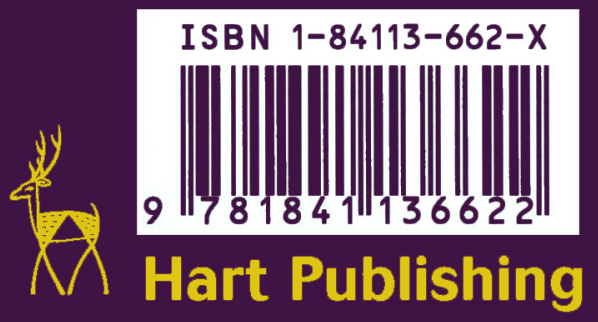

